\title{
Formação Jnicial de Professores e Producãa de Material Didático para o Ensino de Gêneros: Uma Experiência com - Gênero "Regra de Jogo"
}

\author{
Lucas Feitoza DINIZ* \\ Gustavo LIMA** \\ Marcos Apolo Cordeiro SOBRAL JÚNIOR***
}

\begin{abstract}
* Especialista em Metodologia do Ensino em Língua Portuguesa, Literatura e Língua Inglesa pela Faculdade da Região Serrana (2021). Professor da Educação Básica no Colégio Santa Sofia (Garanhuns / PE). Contato: dinizlucasf@gmail.com

** Doutor em Letras/Linguística pela Universidade Federal de Pernambuco (2016). Professor Adjunto III_UFAPE. Contato: ghlima.prof@gmail.com

*** Licenciado em Letras Inglês/Português pela Universidade Federal do Agreste de Pernambuco (2020). Contato: apolojunior7@homail.com
\end{abstract}

\begin{abstract}
Resumo:
Este artigo tem como objetivo apresentar uma proposta de itinerário formativo com vistas à elaboração de um material didático alternativo para o ensino de gêneros nas escolas. Partimos aqui de uma perspectiva de ensino explícito e sistemático de gêneros por meio de ferramentas de ensino diversificadas (SCHNEUWLY, 2009) e de sequências didáticas (DOLZ, NOVERRAZ e SCHNEUWLY, 2004). Também nos apoiamos teoricamente no Modelo Didático de Gênero (DOLZ e SCHNEUWLY, 2004) e na proposta do Banco de dados para materiais didáticos (BMDs) com base em gêneros desenvolvida por Mendonça (2003). A experiência envolvendo a elaboração de materiais didáticos foi vivenciada em uma disciplina do $7^{\circ}$ período do curso de Licenciatura em Letras da Universidade Federal do Agreste de Pernambuco, situada no município de Garanhuns, na região do Agreste Meridional do Estado de Pernambuco. Os resultados apontam para um processo formativo que favoreceu a criatividade e a autonomia dos futuros professores em relação à produção de materiais didáticos autorais para o ensino de gêneros nas aulas de língua portuguesa.
\end{abstract}

Palavras-chave:

Ensino de gêneros; sequência didática; itinerário formativo. 


\title{
Formação Inicial de Professores e Produção de Material Didático para o Ensino de Gêneros: Uma Experiência com o Gênero "Regra de Jogo"
}

\author{
Lucas Feitoza Diniz; Gustavo Lima; Marcos Apolo Cordeiros Sobral Júnior
}

\section{INTRODUÇão}

O trabalho do professor na sala de aula implica, dentre outros aspectos, um processo de decomposição do objeto de ensino por meio da utilização diferentes ferramentas de ensino, as quais, segundo Schneuwly (2009), são agrupadas em duas macro categorias: as ferramentas institucionais e as ferramentas específicas. Esta última pode ainda ser desdobrada em duas subcategorias: o conjunto dos materiais escolares e o conjunto dos discursos elaborados pela escola sobre o objeto a ensinar.

Segundo o autor, a primeira categoria de ferramentas compreenderia os artefatos disponibilizados pelo meio físico escolar, mas que não estão a serviço de um componente curricular específico. Nesse grupo, enquadrar-se-iam, por exemplo, os artefatos tecnológicos, como a lousa, o computador, o projetor multimídia etc. Já as ferramentas específicas, estão intrinsecamente relacionadas ao funcionamento de componentes curriculares específicos, ou seja, configuram-se como "ferramentas que asseguram a apresentação, o encontro e a interação do aluno com o objeto a ser ensinado [...] $]^{1}$ (SCHNEUWLY, 2009, p.33). Enquadram-se nessa categoria, por exemplo, os materiais didáticos específicos para o ensino de língua (livro didático, fichas ou apostilas, obras complementares, mídias digitais pedagógicas etc.) e os discursos elaborados pelas escolas sobre o objeto a ensinar, "as maneiras de dizê-lo, de falar sobre ele, de lhe apresentar verbalmente através da lição, de lhes traduzir em diálogo do tipo pergunta-resposta, etc ${ }^{2}$ " (SCHNEUWLY, 2009, p.33)

Neste artigo, interessa-nos especificamente o desenvolvimento de materiais didáticos alternativos que favoreçam a exploração sistemática do objeto de ensino em sala de aula. Daí a nossa opção metodológica pelas sequências didáticas (DOLZ, NOVERRAZ; SCHNEUWLY, 2004), uma vez que estas, se bem elaboradas, podem ser utilizadas "pelo educador para possibilitar ao aluno o encontro e o estudo do objeto de ensino ou uma de suas dimensões"” (SCHNEUWLY, 2009, p.34).

Essa proposta surgiu a partir da inquietação de alguns alunos acerca do caráter eminentemente teórico do programa do Curso de Licenciatura em Letras proposto pela nossa universidade, o qual, segundo os discentes, ainda parece negligenciar algo indispensável à formação de professores: os saberes a ensinar. Acreditamos que é papel da universidade propor um itinerário formativo que possibilite não só a aquisição de conhecimentos científicos da área de atuação, mas, sobretudo, articular esses conhecimentos a discussões acerca dos objetos de ensino e das possibilidades de ensiná-lo no contexto escolar (DOLZ, LIMA e ZANI, 2000).

\footnotetext{
${ }^{1}$ Tradução nossa. No original: "Il s'agit fondamentalement des outils qui assurent la présentation, la reencontre et interaction de l'élève avc l'objet a enseigner dans la classe [...]"

${ }^{2}$ Tradução nossa. No original: “[...] les manières de le dire, d'em parler, de le présenter verbalement à travers la leçon, de le traduire em dialogue de type question-réponse, etc. [...]"

${ }^{3}$ Tradução nossa. No original: “[...] utilisés par l'enseignant pour permettre à l'èléve de rencontrer et d'étudier l'objet d'enseignant ou l'une de ses dimensions."
} 
Desse modo, este artigo tem como objetivos: a) descrever uma proposta de itinerário formativo com vistas à elaboração de materiais didáticos para o ensino de gêneros; e b) apresentar um material didático alternativo para o ensino do gênero "regra de jogo". Em um primeiro momento, discutiremos, portanto, os aportes teóricos que orientaram a realização do itinerário formativo; em seguida, descreveremos o percurso de elaboração dos materiais didáticos e, por fim, exemplificaremos nossa proposta com uma sequência didática (DOLZ, NOVERRAZ e SCHNEUWLY, 2004) elaborada por dois graduandos em Letras para o ensino do gênero "regra de jogo",

\section{Alicerçando a Proposta...}

Os gêneros são formas relativamente estáveis de comunicação que criam e medeiam situações sociais específicas. O artigo científico, por exemplo, tem características estilísticas e visuais próprias, facilmente reconhecíveis por aqueles que estão inseridos na esfera acadêmica (tamanho de letra, formato de citações, recuos etc.), e serve a um propósito comunicativo definido. Entender o gênero dessa maneira nos situa, a um tempo, na perspectiva bakhtiniana, para quem o gênero só existe enquanto unidade socialmente reconhecida; e na perspectiva sociointeracionista de Vygotsky, segundo a qual a atividade humana é sempre mediada por objetos do mundo cultural - aqui, a linguagem.

Sendo a própria aula um gênero, é preciso entender que quando se ensina gênero, os gêneros da vida cotidiana não serão meramente reproduzidos no ambiente escolar, mas sofrem modificações para serem escolarizados. Longe de negar a continuidade entre a escola e os diferentes locus onde circulam os gêneros, também entendemos a escola como local específico de comunicação. A partir do momento que um exemplar autêntico de um determinado gênero é trabalhado no contexto escolar, ele se torna "uma variação do gênero de referência, construída numa dinâmica de ensino-aprendizagem, para funcionar numa instituição cujo objetivo primeiro é precisamente este" (DOLZ, SCHNEUWLY, 2004, p. 69).

Mesmo entendendo a necessidade e a importância de pôr o gênero textual no centro do trabalho com língua, na escola, não se pode negar que organizar o ensino com base nos gêneros isolados pode ser uma grande dificuldade. Isso porque os gêneros, apesar de razoavelmente estabelecidos formalmente, são “eventos textuais altamente maleáveis, dinâmicos e plásticos” (MARCUSCHI, 2021, p. 1). Principalmente em tempos como os nossos, em que o avanço das tecnologias de informação e comunicação traz consigo mudanças nos locus de circulação dos gêneros e na própria experiência com o gênero (tornando-os mais interativos com o auxílio dos suportes multimodais), além de fomentar novas práticas de linguagem que acabam por criar gêneros novos ou evidenciar fenômenos como o da "hibridização/ intertextualidade intergêneros" (KOCH e ELIAS, 2006, p. 114), caracterizado quando um gênero assume a forma de outro em função do propósito comunicativo.

Sendo quase infinito o número de gêneros (e maior ainda o das possibilidades de intertextualidade intergenérica), o ensino de expressão oral/escrita não pode se orientar pelos gêneros isolados - sob o risco de voltar à tradição escolar da redação e composição - mas desenvolver, a partir do trabalho sistemático com gêneros de diferentes ordens, capacidades de linguagem que sejam transferidas entre gêneros da mesma ordem discursiva. A abordagem em sala de aula de gêneros como a carta de opinião, para além das características particulares desse gênero, deve, por exemplo, desenvolver a capacidade de sustentação, refutação e tomadas de posição, que são aplicáveis também em outros gêneros como a assembleia, o debate regrado e a resenha crítica. É nessa linha de pensamento que Dolz, Noverraz e Schneuwly (2004) propõem o conceito de agrupamentos de gêneros, enquanto instrumentos organizadores do currículo. Os cinco agrupamentos propostos pelos autores compreendem as ordens do narrar (organizar experiências ficcionalmente), relatar (organizar experiências vividas, situadas no tempo), descrever ações (gêneros voltados 
para a regulação dos comportamentos), argumentar (assumir, refutar e defender tomadas de posição) $e$ expor (textualizar diferentes saberes).

Tais agrupamentos coordenam um trabalho orientado não para a mera apropriação das características individuais de um determinado gênero, mas para o desenvolvimento de capacidades de linguagem globais transferíveis entre os diferentes gêneros (de um mesmo agrupamento ou mesmo transagrupamentos, já que a própria classificação dos gêneros em um agrupamento ou outro é fluida) a serem construídas no trabalho com esses diferentes agrupamentos, representados por gêneros variados ao decorrer da vida escolar. O conceito de agrupamentos facilita a progressão (a organização temporal do ensino para que ele resulte em uma aprendizagem ótima), que pode se organizar a partir deles e não apenas dos gêneros isolados, garantindo assim uma visão global da aprendizagem nos diferentes ciclos (progressão interciclos) e no interior de cada ciclo (progressão intraciclos).

Para que o trabalho com o gênero seja efetivo e possibilite não só sua apropriação, mas o desenvolvimento das capacidades globais de linguagem, Dolz, Noverraz e Schneuwly (2004) propõem, como instrumento articulador da progressão, a sequência didática, "um conjunto de atividades escolares organizadas, de maneira sistemática, em torno de um gênero textual oral ou escrito" (DOLZ, NOVERRAZ, SCHNEUWLY, 2004, p. 97). Vale lembrar que mesmo se focando em um único gênero, a sequência didática possibilita não apenas a apropriação daquele gênero em específico, já que sua organização em módulos favorece levar as reflexões desenvolvidas para outros gêneros do mesmo agrupamento.

A sequência didática, conforme definida por Dolz, Noverraz e Schneuwly (2004), é constituída de quatro etapas. Na primeira, chamada apresentação da situação, os alunos tomam contato com um problema de comunicação bem definido (pelo gênero a ser estudado na sequência didática) e para o qual toda a sequência estaria orientada. Para uma sequência didática, por exemplo, sobre o gênero verbete, os alunos podem ser convidados a criar um glossário de expressões que eles usam na internet. A situação comunicativa do glossário cria o gênero (verbete) e todas as etapas de sequência culminarão na produção dessa enciclopédia com os verbetes.

A partir da apresentação da situação, os alunos são convidados a fazer uma primeira producão, partindo apenas do contato com o gênero na apresentação da situação. A ideia é que os estudantes mobilizem os conhecimentos prévios em gêneros naquele agrupamento. A partir dessa primeira produção, o professor pode identificar as maiores dificuldades/necessidades da turma e a partir delas, organizar os módulos, que são as atividades específicas e variadas através das quais o professor vai trabalhar sistematicamente as características do gênero em questão. Ao final dos módulos, os alunos serão capazes não só de realizar a produção final, consolidando seus conhecimentos sobre o gênero estudado, mas também de se autoavaliar e de sistematizar as características daquele gênero.

Em síntese, a sequência didática apresenta-se como um instrumento facilitador da prática docente, por subsidiar estratégias que podem ser facilmente adaptadas à realidade de cada sala de aula, graças à sua estrutura em módulos.

\section{Os Caminhos de Elaboração de Materiais Didáticos para o ENSINo DE GÊNEROS}

A ideia de elaboração de materiais didáticos para o ensino de gênero surgiu em 2016, no âmbito da disciplina de Didática e Avaliação da Aprendizagem, ofertada no $7^{\circ}$ período do curso de Licenciatura em Letras da então Unidade Acadêmica de Garanhuns (UAG), vinculada à Universidade Federal Rural de 
Pernambuco (UFRPE) ${ }^{4}$. A referida disciplina possui uma carga-horária de $60 \mathrm{~h}$ e tem como objetivo oferecer subsídios teórico-metodológicos que auxiliem os futuros professores a refletirem sobre questões em torno do ensino, em especial aspectos da didática e da avaliação no componente curricular de Língua Portuguesa.

Uma das demandas recorrentes dos discentes nessa disciplina é em relação a quais são as possibilidades didáticas - e isso inclui as ferramentas de ensino e dispositivos didáticos - de viabilizar o trabalho com uma concepção interacionista de língua e linguagem na sala de aula. E foi justamente esse o motivo que nos levou a propor um itinerário formativo que possibilitasse aos professores em formação a elaboração de materiais didáticos para o ensino de gêneros, o que nos levou a opção metodológica pelo dispositivo da sequência didática.

Abaixo, apresentamos um recorte dos gêneros contemplados nas sequências didáticas elaboradas pelos graduandos entre os períodos de 2016.1 e 2019.2, com exceção dos períodos letivos referentes a 2017, ano em que a disciplina não estava sob a regência do professor responsável. Vejamos:

Quadro 1: Gêneros contemplados nas SD

\begin{tabular}{|c|c|}
\hline SEMESTRE & GÊNEROS \\
\hline \multirow{5}{*}{2016.1} & Notícia \\
\hline & Artigo de Opinião \\
\hline & Conto \\
\hline & Artigo científico \\
\hline & Narrativa de aventura \\
\hline \multirow{4}{*}{2016.2} & Cordel \\
\hline & Artigo de opinião \\
\hline & Notícia \\
\hline & Entrevista \\
\hline \multirow{5}{*}{2018.1} & Carta do Leitor \\
\hline & Peça Teatral \\
\hline & Meme \\
\hline & Relato de viagem \\
\hline & Fotografia jornalística \\
\hline \multirow{9}{*}{2018.2} & Descrição do Perfil do YouTube \\
\hline & Tutorial \\
\hline & Regra de jogo \\
\hline & Mangá \\
\hline & Sinopse de filme \\
\hline & Poema \\
\hline & Roteiro \\
\hline & Meme \\
\hline & Relato de viagem \\
\hline
\end{tabular}

${ }^{4}$ Após processo de emancipação, a Unidade Acadêmica de Garanhuns passou a ser denominada, no início de 2020, de Universidade Federal do Agreste de Pernambuco. 


\begin{tabular}{|c|c|}
\hline \multirow{4}{*}{2019.1} & Meme \\
\cline { 2 - 2 } & Anúncio publicitário \\
\cline { 2 - 2 } & Entrevista \\
\cline { 2 - 2 } & Seminário \\
\cline { 2 - 3 } & Relato de viagem \\
\cline { 2 - 3 } & Resenha crítica \\
\hline \multirow{4}{*}{2019.2} & Rótulo \\
\hline \multirow{4}{*}{} & Debate Regrado \\
\cline { 2 - 3 } & Fábula \\
\cline { 2 - 3 } & Anúncio publicitário \\
\cline { 2 - 3 } & Cordel \\
\cline { 2 - 3 } & Repente \\
\cline { 2 - 3 } & Cartaz digital \\
\cline { 2 - 3 } & Podcast \\
\cline { 2 - 3 } & Debate regrado \\
\hline
\end{tabular}

Fonte: Lima, Mariano e Xavier (no prelo)

O quadro acima revela uma incidência maior de gêneros escritos, totalizando 21 ocorrências $^{5}$; seguido de gêneros que mesclam múltiplas semioses, com 09 ocorrências $^{6}$; e, por fim, os gêneros orais, os quais contabilizaram apenas 08 registros ${ }^{7}$. Acreditamos que o fato de os graduandos, em sua maioria, terem escolhido gêneros escritos para a elaboração de sequências didáticas talvez tenha relação com o poder que a cultura do escrito exerce na sociedade e na tradição escolar. Sobre a presença pouco representativa de gêneros orais, atribuímos ao fato de o oral ainda não ser efetivamente tomado como objeto a ensinar nas escolas (DOLZ, SCHNEUWLY e HALLER, 2004; ASSUNÇÃO, MENDONÇA e DELPHINO, 2013; CARVALHO e FERRAREZI JR., 2018).

O processo de elaboração do material didático ocorreu em 6 (seis) etapas. Em um primeiro momento, foram selecionados textos científicos de referência sobre o ensino explícito e sistemático dos gêneros, dentre eles, o intitulado "Sequências didáticas para o oral e a escrita: apresentação de um procedimento", de autoria de Joaquim Dolz, Michèle Noverraz e Bernard Schneuwly.

Após a leitura prévia desse texto e da discussão em sala sobre o tema, partimos para a escolha do gênero da sequência didática. Para tal, a turma foi dividida em duplas e o desafio foi lançado: escolher um gênero que ainda era pouco didatizado nos materiais didáticos disponíveis no mercado editorial, tais como apostilas e livros didáticos. O objetivo era o de despertar a criatividade dos alunos no sentido de desenvolverem materiais didáticos alternativos que pudessem explorar outras possibilidades de ensino de gêneros orais e escritos na sala de aula.

A etapa seguinte consistiu na análise de 5 a 10 exemplares de gênero com base em alguns critérios previamente estabelecidos. O objetivo era o de fazer com que os alunos conhecessem mais a fundo o gênero e, por conseguinte, fossem capazes de definir as suas dimensões ensináveis a partir da elaboração de um modelo didático do gênero (DOLZ e SCHNEUWLY, 2004), o qual não se caracteriza por padrões fixos imutáveis. Ao contrário, esse modelo é retroalimentado por ser suscetível a variabilidade das práticas

${ }^{5}$ Relato de viagem (3), Artigo de opinião (2), Cordel (2), Notícia (2), Carta do leitor (1), Conto (1), Artigo científico (1), Narrativa de aventura (1), Descrição do perfil do YouTube (1), Tutorial (1), Regra de jogo (1), Sinopse de filme (1), Poema (1), Roteiro (1), Resenha Crítica (1) e Fábula (1).

${ }^{6}$ Anúncio publicitário (2), Meme (3), Cartaz digital (1), Rótulo (1), Mangá (1) e Fotografia jornalística (1).

${ }^{7}$ Debate regrado (2), Entrevista (2), Seminário (1), Peça Teatral (1), Repente (1) e Podcast (1). 
sociais que determinam o funcionamento e, por conseguinte, as regularidades dos gêneros. Por essa razão, entendemos que a elaboração desse modelo não deve prescindir de uma leitura atenta e de uma análise minuciosa de um corpus autêntico, representativo e diversificado do gênero a ser didatizado, de forma que possamos traçar uma caracterização desse gênero, identificando, por exemplo, suas regularidades linguísticas, sua composição, sua finalidade comunicativa e os lugares sociais onde se realiza.

De forma a auxiliar os alunos nesse processo, adaptamos o Banco de dados para materiais didáticos (BMD) com base em gêneros proposto por Mendonça (2003). A seguir, o quadro utilizado pelos alunos para a análise dos exemplares do gênero:

Quadro 2: orientações para a análise e a elaboração de modelos didáticos de gêneros

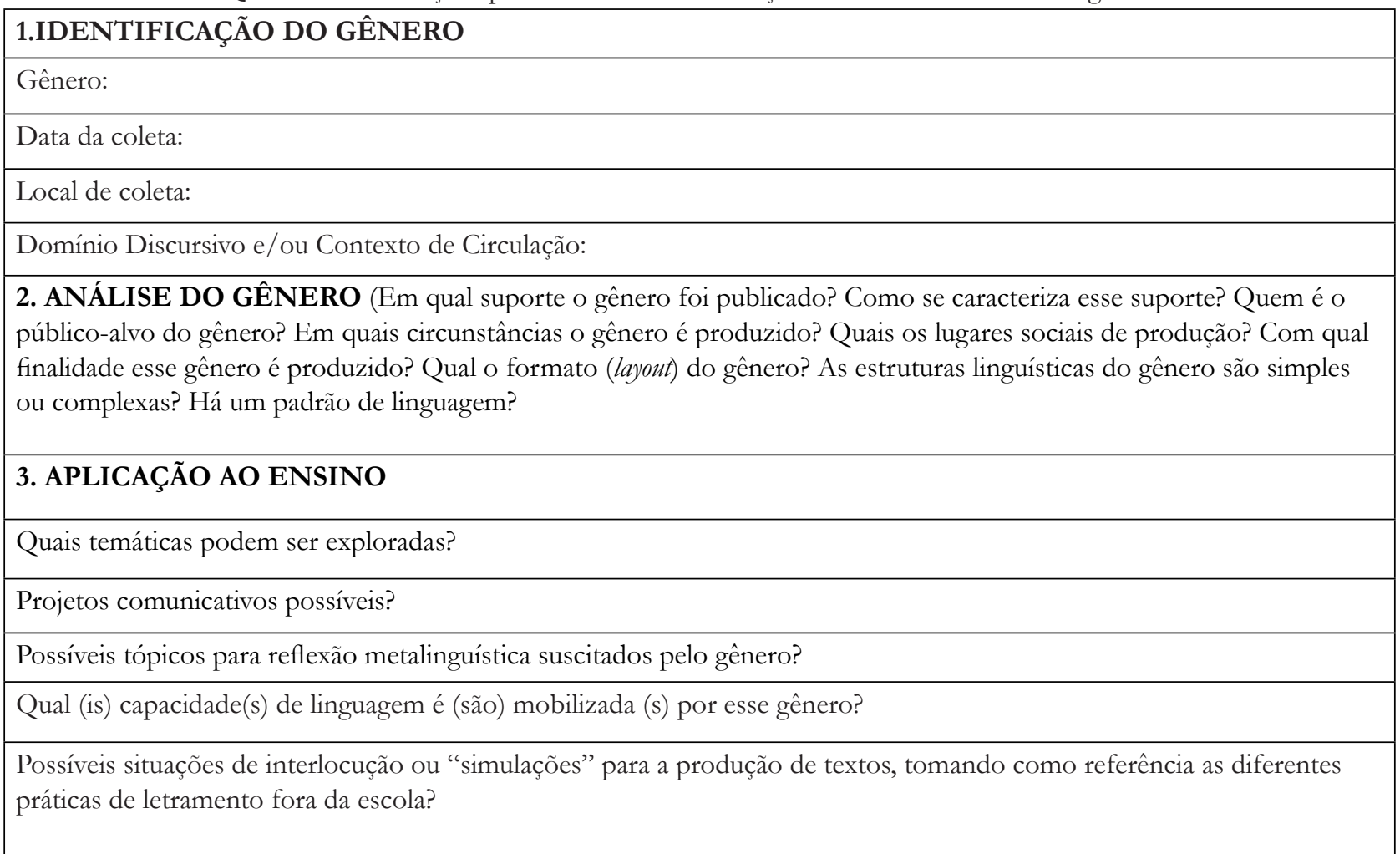

Adaptado da proposta de Mendonça (2003)

De posse dos conhecimentos necessários sobre o gênero, as duplas deram início a elaboração das sequências didáticas considerando o projeto comunicativo, os objetivos de ensino e de aprendizagem, as estratégias e os recursos didáticos, os conteúdos a serem trabalhados e as capacidades de linguagem a serem desenvolvidas. A proposta ainda incluía a redação de um pequeno texto didático sobre o gênero destinado ao professor.

A etapa posterior foi a de socialização do material didático produzido em um evento de extensão ${ }^{8}$ da nossa universidade intitulado Seminário sobre Didática do Ensino de Língua Portuguesa (SEDELP) ${ }^{9}$. O público-alvo era constituído pelos demais alunos do curso, a comunidade acadêmica como um todo, professores das redes públicas e privadas de ensino e o público em geral. Na ocasião, as sequências didáticas também eram avaliadas por professores convidados, e pesquisadores da área de linguagem e da educação.

\footnotetext{
${ }^{8}$ Evento constitutivo do projeto de extensão do Núcleo de Pesquisa em Discurso e Ensino (NUPEDE/CNPq).

${ }^{9}$ Inicialmente o evento ocorria de forma presencial, em sessões de Pôster, na universidade. Porém, em função do contexto de pandemia provocado pela Covid-19, as últimas edições têm sido realizadas de forma on-line.
} 
A etapa final será a publicação das sequências em um repositório digital de materiais didáticos para o professor e em também em uma coletânea ${ }^{10}$. A título de exemplificação dos materiais didáticos desenvolvidos para o ensino de gêneros, apresentaremos, a seguir, uma sequência com o gênero "regra de jogo", produzida por dois licenciandos em Letras, no período de 2018.2.

\section{O JOGO DO MUNDO, O JOGO NO MUNDO: UMA PROPOSTA DE MATERIAL DIDÁTICO PARA O ENSINO DO GÊNERO REGRA DE JOGO NO CONTEXTO ESCOLAR}

Os jogos, sejam eletrônicos ou de tabuleiro, fazem parte da vivência dos alunos e podem estimular o relacionamento entre indivíduos, seja colaborativa ou competitivamente.

O gênero Regra de Jogo possui uma gama de especificidades e de situações de ensino de língua portuguesa que são interessantes de serem trabalhadas em sala de aula. Além de mobilizar o lúdico e o educativo, o trabalho com a regra de jogo sistematiza as habilidades de regulação dos comportamentos em grupos sociais, que os alunos já conhecem do ambiente escolar ou extraescolar (família, por exemplo). Assim, o trabalho com a regra de jogo exerce "funções com base na convivência, respeito ao próximo e a si mesmo, [que] devem acompanhar o estudante ao longo da vida (...), relacionadas à percepção de mundo [e] em relação à cultura” (PARANÁ, 2008 apud RACHWAL, 2018, p. 7-8) ${ }^{11}$.

A regra de jogo é um gênero textual classificado no agrupamento do descrever ações, cujo domínio social de comunicação é o das instruções e prescrições, mobilizando a capacidade de linguagem da regulação mútua dos comportamentos (SCHNEUWLY; DOLZ, 2004). Algumas de suas características, de acordo com Rachwal (2018), são:

- Uso da função apelativa da linguagem, à medida que prescrevem ações a serem realizadas a fim de atingir o objetivo proposto (p. 22);

- Uso do verbo no modo imperativo ou na forma infinitiva (p. 22);

- Preferência por instruções curtas e objetivas, organizadas em itens;

- Leva em consideração o interlocutor real (mesmo que seja idealizado dentro de determinada faixa etária), para definir o nível de complexidade do texto de modo a instruir claramente sobre o jogo.

Considerando a utilidade do modelo de sequência didática para a formação de professores, enquanto subsídio de estratégias para um ensino-aprendizagem ótimo de língua materna, propomos, a título de exemplo, uma sequência didática para o ensino do gênero regra de jogo. Esse material foi produzido como atividade avaliativa na disciplina de Didática e Avaliação da Aprendizagem, ministrada no segundo semestre de 2018 pelo professor Gustavo Lima na (então) Unidade Acadêmica de Garanhuns da Universidade Federal Rural de Pernambuco (UFRPE - UAG).

Nosso critério de escolha para esse gênero baseou-se na análise feita por Diniz e Lima (2017) das propostas curriculares dos municípios de Caetés e Garanhuns, na região do Agreste Meridional de

\footnotetext{
${ }^{10}$ Essa última etapa ainda não foi consolidada. As sequências ainda estão sendo sistematicamente revisadas e formatadas para posterior publicação.

${ }^{11}$ As inserções em colchetes são nossas e têm como objetivo melhorar a coesão do texto original, cuja falta de conectores em determinados momentos prejudica a clareza.
} 
Pernambuco, onde está situada a Unidade Acadêmica. Tal pesquisa ${ }^{12}$ verificou que os gêneros da ordem do descrever ações, nos anos finais do Ensino Fundamental, eram os menos contemplados dentre todos os outros agrupamentos, sendo proposto o trabalho de maneira sistemática em apenas uma unidade didática, em um único ano letivo. Assim, pensamos em propor aos professores da região adjacente à Universidade um instrumento para sanar essa deficiência no currículo, sempre e quando essa necessidade parta das capacidades, expectativas e necessidades dos alunos, que são os critérios a partir dos quais o currículo deve se organizar para diferenciar-se do programa escolar (centrado e recortado a partir dos conteúdos).

A sequência didática a seguir foi pensada para uma turma do $7^{\circ}$ ano do Ensino Fundamental, em dez momentos, que compreendem as quatro etapas descritas por Dolz, Noverraz e Schneuwly (2004) apresentação da situação, produção inicial, módulos e produção final. Pensamos cada etapa para a duração de 2 horas-aula. O objetivo era o de proporcionar, aos alunos, elementos para reflexão e sistematização a respeito do gênero regra de jogo, de tipologia injuntiva. De forma específica, a sequência didática proposta visava: a) auxiliar na produção de novas regras de jogo para jogos já existentes; b) estimular a criatividade e a capacidade dos alunos de articular, a partir da linguagem, a regulação de comportamentos; e c) proporcionar eventos de letramento para socializar o conhecimento linguístico adquirido.

No primeiro momento, que compreende a etapa chamada por Dolz, Noverraz e Schneuwly (2004, p. 98) de "apresentação da situação", o professor pode apresentar alguns jogos aos estudantes e pede-lhes que, organizados em duplas/grupos, joguem esses jogos. A seleção de jogos para a atividade deve tomar em conta as práticas sociais e preferências dos estudantes, de modo que eles sejam familiares aos jogos apresentados13. Ao final das partidas, os estudantes deverão sistematizar, por escrito, as regras do jogo que acabaram de jogar - a "produção inicial" (DOLZ; NOVERRAZ; SCHNEUWLY, 2004). Ao final dessa primeira produção, evidenciar que, ao término da sequência, eles serão capazes de reescrever esses textos, inserindo novas regras nos jogos já existentes, e que essas produções serão socializadas com a comunidade escolar num salão de jogos.

$\mathrm{Na}$ segunda etapa, começam os módulos nos quais serão exploradas, de maneira sistemática e variada, as características do gênero regra de jogo. Os módulos aqui propostos são sugestões levantadas a partir das características prototípicas do gênero, podendo (e devendo) ser adaptados pelo professor tendo em vista as capacidades e necessidades de aprendizagem dos seus alunos. No primeiro módulo, os alunos, divididos nos mesmos grupos da etapa anterior, poderão jogar novamente os mesmos jogos da aula anterior, dessa vez seguindo a regra oficial/institucional do referido jogo. Ao fim das partidas, através de uma roda de conversa, eles irão comparar a experiência do jogo segundo as regras conhecidas por eles (usadas na primeira etapa) e segundo a regra oficial.

Para o segundo módulo, os alunos (novamente distribuídos em grupos) receberão para leitura regras de jogo adaptadas na forma de um texto corrido, e deverão jogar os jogos seguindo essas regras. A intenção é que eles percebam a importância da topicalização na estrutura do gênero. Em seguida, pede-se para que os alunos organizem o texto corrido em tópicos simples e de fácil compreensão.

Já no terceiro módulo, a sugestão é organizar os estudantes em grupos. Nessa etapa, os grupos socializam suas regras topicalizadas na aula anterior com os demais grupos. A partir daí, a turma vai se autoavaliando e refinando as produções mutuamente.

\footnotetext{
${ }^{12}$ Pesquisa realizada no âmbito do Programa de Iniciação Científica da UFRPE, no período de 2016 a 2017, sobre agrupamento e progressão de gêneros nos currículos de duas cidades da Região do Agreste Meridional de Pernambuco.

${ }^{13}$ Algumas sugestões de jogos são: jogo da velha, UNO, Pokémon Trading Card Game, jogo de tabuleiro Monopoly, jogo do Mário etc.
} 
No quarto módulo, os estudantes, novamente organizados em grupos, deverão circular os verbos que encontrarem no texto (se necessário, o professor pode revisar essa categoria gramatical com os estudantes antes). Após isso, o professor poderá elencar no quadro os verbos localizados e faz uma análise comparativa desses vocábulos, mobilizando questões como:

- A quem (=que interlocutor) esses verbos se dirigem?

- Quais as semelhanças entre esses verbos? Em que tempo verbal estão situadas as ações?

- O que eles expressam?

Tais questões precisam ser mobilizadas, se possível, a partir do conhecimento dos alunos. A partir dessa sistematização, os alunos irão perceber que o gênero regra de jogo faz uso de verbos sempre no presente, no modo imperativo, podendo estar na forma infinitiva. Após essa discussão, pedir que os grupos revisem o uso dos verbos nas suas produções e façam os ajustes necessários.

Para o quinto módulo, o professor precisa entregar aos alunos versões modificadas por ele próprio das regras que os alunos estão produzindo, e pedir-lhes que joguem os jogos seguindo essas regras modificadas. Em seguida, a proposta é problematizar a ideia do jogo como regulação social, já que as regras que ele inseriu precisam ser debatidas pelos jogadores antes de seu uso: por exemplo, por que não usar combinações diferentes para o jogo da velha que não sejam as clássicas horizontal, vertical e diagonal? Ou grades com mais de 9 espaços para esse jogo? A partir disso, solicitar que os alunos (a depender do jogo pelos quais estão responsáveis), criem uma nova regra para inserir nas regras do jogo que eles já têm.

No sexto módulo, os alunos deverão jogar os jogos seguindo as regras produzidas na aula anterior. Se necessário, pedir-lhes que revisem a regra que criaram, a partir das dificuldades encontradas na partida (se houver). Esse é o momento mais sistemático de reescrita. Quando todos os grupos têm regras autorais satisfatórias, o professor pede-lhes que, oralmente, sistematizem as características do gênero regra de jogo, que o professor elenca no quadro para registro posterior dos alunos no caderno.

Para o sétimo módulo, faz-se necessário o uso de um computador, smartphone e projetor. Com auxílio desses recursos tecnológicos, o professor deve apresentar a regra dos jogos que vêm sendo explorados em sala em um ambiente virtual (simulador/ jogo eletrônico). Pedir-lhes que joguem no ambiente virtual e que, em seguida, discutam as diferenças entre a regra por escrito e a regra no ambiente virtual. A partir da discussão, propor que o salão de jogos deverá ter duas versões da regra de jogo produzida: uma por escrito, em cartolina, para ser afixada próximo à mesa onde estará cada jogo; e uma oral, que será usada para apresentar, aos visitantes, o jogo de cada grupo, ensinando-os a jogar. Pedir-lhes que produzam o cartaz e que sistematizem as informações a serem oralizadas na apresentação.

O nono momento é destinado à "produção final" (DOLZ; NOVERRAZ; SCHNEUWLY, 2004, p. 98): os grupos socializam suas regras de jogo entre si, numa versão interna do que virá a ser o salão de jogos. O professor aproveita esse momento para fazer os últimos ajustes na produção dos alunos, que deverão entregar uma versão escrita da regra produzida, além de fixá-la em cartaz e apresentá-la oralmente no salão de jogos.

O décimo (e último) momento marca a realização do projeto comunicativo "Salão de Jogos", momento no qual os alunos ensinarão aos colegas de outras turmas a como jogar os jogos pelos quais ficaram responsáveis, usando para isso as regras que eles mesmos produziram. Culminar a sequência didática com uma situação autêntica do uso das regras de jogo evidencia, para os estudantes, a mobilização das capacidades de linguagem desenvolvidas em situações concretas da vida cotidiana: o gênero continua 
gênero para ensinar/aprender, sem deixar de ser gênero para comunicar, reforçando o papel da escola não como o único, mas um dos muitos locus de circulação dos diferentes gêneros.

\section{Encerrando a Partida...}

Numa interface com a dimensão da pesquisa e da extensão universitária, o itinerário formativo com vistas ao desenvolvimento de sequências didáticas inscreve-se em um movimento que visa propor o uso de materiais didáticos alternativos que contribuam para o desenvolvimento do trabalho do professor em sala de aula.

Como vimos na experiência relatada, as etapas de elaboração do material didático para o ensino de gêneros incluíram a leitura de textos científicos, a seleção e a análise de exemplares do gênero a ser didatizado, a elaboração, o compartilhamento e a publicação das produções dos discentes. Nesse processo, realizado de forma colaborativa, estão implicados aspectos cruciais à formação docente, tais como a operacionalização de saberes científicos à ação didática, a troca de conhecimentos e experiências entre o professor formador e os futuros professores, a avaliação contínua da aprendizagem dos alunos e a reflexão conjunta acerca de um agir didático prospectivo.

Em suma, o desafio de propor aos futuros professores a elaboração de materiais didáticos alternativos para o ensino de gêneros tem, até então, se apresentado como uma alternativa metodológica viável rumo à construção de um paradigma de formação inicial de professores pautado no debate sobre as ferramentas de ensino e as possibilidades de transposição didática dos objetos de ensino.

\section{REFERÊNCIAS}

ASSUNÇÃO, A. de A. de; MENDONÇA, M. do C. C.; DELPHINO, R. M. Pouca ênfase no desenvolvimento da competência oral dos alunos. In: BORTONI-RICARDO, S. M.; MACHADO, V. R. (orgs). Os dozes trabalhos de Hércules: do oral para o escrito. São Paulo: Parábola, 2013, p. 165-177.

CARVALHO, R. S. de; FERRAREZI Jr, C. Oralidade: conceito e relevância. In: Oralidade na educaşão básica: o que saber, como ensinar. São Paulo: Parábola, 2018, p. 13-37.

DINIZ, L. F.; LIMA, G. Agrupamento e progressão de gêneros em duas propostas curriculares da região do agreste meridional de Pernambuco. Travessias Interativas. 2017. Disponível em: < http:/ / travessiasinterativas.com.br/?view $=\mathrm{v} 14 \mathrm{n} 2>$ Acesso em: 06 jan. 2018.

DOLZ, J.; LIMA, G.; ZANI, J. B. Itinerário para o ensino do gênero fábula: a formação de professores em um minicurso. Revista Textura. 2020. v.22. n. 52, p. 250-274. Acesso em: 12 jan. 2021.

DOLZ, J.; NOVERRAZ, M.; SCHNEUWLY, B. Sequências didáticas para o oral e a escrita: apresentação de um procedimento. In: DOLZ, J.; SCHNEUWLY, B. Gêneros orais e escritos na escola. Campinas, SP: Mercado de Letras, 2004. pp. 81-108.

DOLZ, J.; SCHNEUWLY, B.; HALLER, S. O oral como texto: como construir um objeto de ensino. In: SCHNEUWLY, B.; DOLZ, J. Gêneros orais e escritos na escola. Tradução e organização de Roxane H. R. Rojo e Glaís S. Cordeiro. 3. ed. Campinas, SP: Mercado de Letras, 2004, p. 125-155.

DOLZ, J.; SCHNEUWLY, B. Os gêneros escolares: das práticas de linguagem aos objetos de ensino. In: DOLZ, J.; SCHNEUWLY, B. (org). Gêneros orais e escritos na escola. Campinas, SP: Mercado de Letras, 2004, p. 61-77. 
KOCH, I. V.; ELIAS, V. M. Gêneros textuais. In: Ler e compreender: os sentidos do texto. São Paulo: Contexto, 2006, p. 101-122.

LIMA, G.; MARIANO, R. C. S.; XAVIER, W. P.. Produção de material didático para o ensino do oral: desafios e possibilidades na formação inicial de professores. In: MAGALHÃES, T. G.; BUENO, L.; NEGREIROS, G. R. C.; COSTA-MACIEL, D. A.G. (orgs.). Oralidade e gêneros orais: experiências na formação docente. São Paulo: Pontes Editores (no prelo).

MARCUSCHI, L. A. Gêneros textuais: definição e funcionalidade. Disponível em https://edisciplinas.usp. br/pluginfile.php/133018/mod_resource/content/3/Art_Marcuschi_Gêneros_textuais_definições_ funcionalidade.pdf>. Acesso em: 23 mar. 2021.

MENDONÇA, M.. Formação do Professor e Letramento Escolar: Projetos Temáticos E Gêneros Textuais. Trabalho apresentado na seção de Comunicações Coordenadas "Gêneros textuais, projetos temáticos e letramento: da formação do professor à sala de aula”, no Seminário Letramento e Alfabetização, no 14o COLE (Congresso de Leitura do Brasil), realizado em julho de 2003, na Unicamp. Disponível em: http://alb.com.br/arquivo-morto/edicoes_anteriores/anais14/Cinda.html. Acesso em: 14 mai. 2016.

PARANÁ. Diretrizes Curriculares de Lingua Portuguesa para a Educação Básica. Disponível em http:/ /www. seed.pr.gov.br/portals/portal/diretrizes. Acessado em: 21 set. 2008.

RACHWAL, S.C.R. Gênero instrucional "regras do jogo": uma proposta de ação pedagógica.

Disponível em: http://www.diaadiaeducacao.pr.gov.br/portals/pde/arquivos/407-4.pdf. Acesso em: 16 nov. 2018.

SCHNEUWLY, B. Le travail enseignant. In: SCHNEUWLY, B.; DOLZ, J. Des objets enseignés en classe de français: Le travail de l'enseignant sur la rédaction de textes argumentatifs et sur la subordonnée relative. Genève: Presses Universitaires de Rennes, 2009. p. 29-43. 